\title{
The Titanic Game: Introducing Game Heuristics to Mixed Methods Theorizing and Data Analysis
}

Journal of Mixed Methods Research 2020, Vol. I4(4) 522-544 (c) The Author(s) 2019 Article reuse guidelines: sagepub.com/journals-permissions DOI: I0.1 I77/I5586898|9885723 journals.sagepub.com/home/mmr

\section{Jörg Stolz' ${ }^{\prime}$ and Anaïd Lindemann'}

\begin{abstract}
Despite tremendous interest in social games and game studies, the potential of game heuristics for the field of mixed methods remains unknown. This article introduces game heuristics to mixed methods research, showing how it was used in a specific study on the survival probabilities on the Titanic. Specifically, we describe how game heuristics was used to create the explanandum, code and interpret the qualitative material, and set up and interpret the quantitative model. Furthermore, we show and explicate how game heuristics was used to construct seven types of meta-inferences. The Titanic data set is especially interesting, since it is routinely used for statistical mono-method teaching; however, it can be shown that a mixed methods approach leads to a better explanation.
\end{abstract}

\section{Keywords}

mixed methods, Titanic, theory construction, integrated data analysis, game heuristics

On the Titanic, the probability of survival differed greatly for men and women, and for members of different classes and crew-no wonder, then, that the Titanic data have become immensely popular in teaching statistical methods in all major statistical packages (SPSS, Stata, R, SAS; Bellocco \& Algeri, 2013; Harrell, 2015; Kohler \& Kreuter, 2017; Landau \& Everitt, 2004). In a recent article, Stolz, Lindemann \& Antonietti (2018) have demonstrated the distinctive advantages of mixed methods when analyzing the Titanic incident compared with approaches that use only quantitative data (Frey, Savage, \& Torgler, 2011; Gleicher \& Stevans, 2004; Hall, 1986). ${ }^{1}$ In fact, a mixed methods account can not only fit a reasonable statistical model to the data but also investigate the exact mechanisms leading to the differences observed.

This is a companion article to the text by Stolz, Lindemann \& Antonietti (2018). That article gave a substantive analysis that could only briefly touch on the underlying game heuristic premises. The goal of this article is to introduce the new methodology of game heuristics to mixed methods research by describing in detail how game heuristics was used to create the explanandum (i.e., the phenomenon to be explained), code and interpret the qualitative material, and set up and interpret the quantitative model. We also identify seven types of meta-inferences that were used to reconstruct the overall social game and the game mechanisms that created the

'University of Lausanne, Lausanne, Switzerland

\section{Corresponding Author:}

Jörg Stolz, ISSR, University of Lausanne, I0I5 Lausanne, Switzerland.

Email: joerg.stolz@unil.ch 
different survival probabilities on the Titanic. Since our goal is to show the use of game heuristics in action with respect to a specific research project, we draw on selected material from the substantive article (Stolz, Lindemann \& Antonietti, 2018), where interested readers can find the full methodological details and all the results. ${ }^{2}$

In the mixed methods literature, there exists an extensive discussion concerning the theoretical and methodological tools best to be used when engaging in mixed methods research (Bazeley, 2017; Creamer, 2018; Creswell \& Plano Clark, 2018; Fetters, Curry, \& Creswell, 2013; Teddlie \& Tashakkori, 2009; Stolz, 2016). We believe that game heuristics may be an interesting methodology to be added to the mixed methods researchers' toolbox. This methodology uses the concept of "social game" (and its different elements) as a theoretical and methodological starting point to think theoretically about social phenomena. Social games have elements that are evidently meaning based and that have to be "understood" qualitatively (e.g., rules, representations). But they also have inputs and outputs that may be counted, measured, and explained quantitatively (e.g., player attributes, game scores).

Showing that an explanation of the survival rates on the Titanic is more convincingly effectuated with a mixed methods and game heuristics framework than with a monomethod approach is attractive for two reasons. On one hand, the Titanic data are very well-known and widely employed to teach statistics and monomethod approaches. On the other hand, the quantitative and qualitative data sets are freely available and can, therefore, be used for teaching mixed methods.

\section{The Titanic Incident}

The Titanic, we remember, hit an iceberg on April 14, 1912, at 11:40 p.m. and had sunk completely about 2 hours and 40 minutes later, at about 2:20 a.m. (Eaton \& Haas, 2011; Lord, 1956/ 2012; Ruffman, 2013). The survival rates of different groups of men and women, and of different classes or types of crew, differed greatly (Figure 1). Thus, women across all classes and crew were generally more likely to survive than men, and higher class passengers, more likely than lower class passengers. There were interesting interactions between gender and class in that women passengers in first and second classes were much more likely to survive than women in third class, while men in first class were much more likely to survive than men in second and third classes. There were also intriguing exceptions and specific findings. For example, deck crewmen had a very high probability of survival, even higher than women passengers in third class, while restaurant crewmen had the lowest probability of survival. The sociological question is, of course, "Why, or through what causal mechanisms, did these differences occur?"

\section{Mixed Methods Theorizing, the Theory of Social Games, and Game Heuristics}

In our mixed methods study on the Titanic, we used the theory of social games and the methodology of game heuristics as the basis of our theory (see key terms in Table 1). This meant conceptualizing the events on the Titanic as a social game (or, rather, as a multiplicity of interlinked games). We deal in this part of our article with the theory of social games, game heuristics, and its application.

Three levels have to be distinguished: the theory of the social game, game heuristics, and the resulting game model. On the first level, the theory of social games consists of the general description of the highly abstract concept of "social game" and its element, as well as the interrelations of these elements. At this level, the theory of social games gives what Merton 


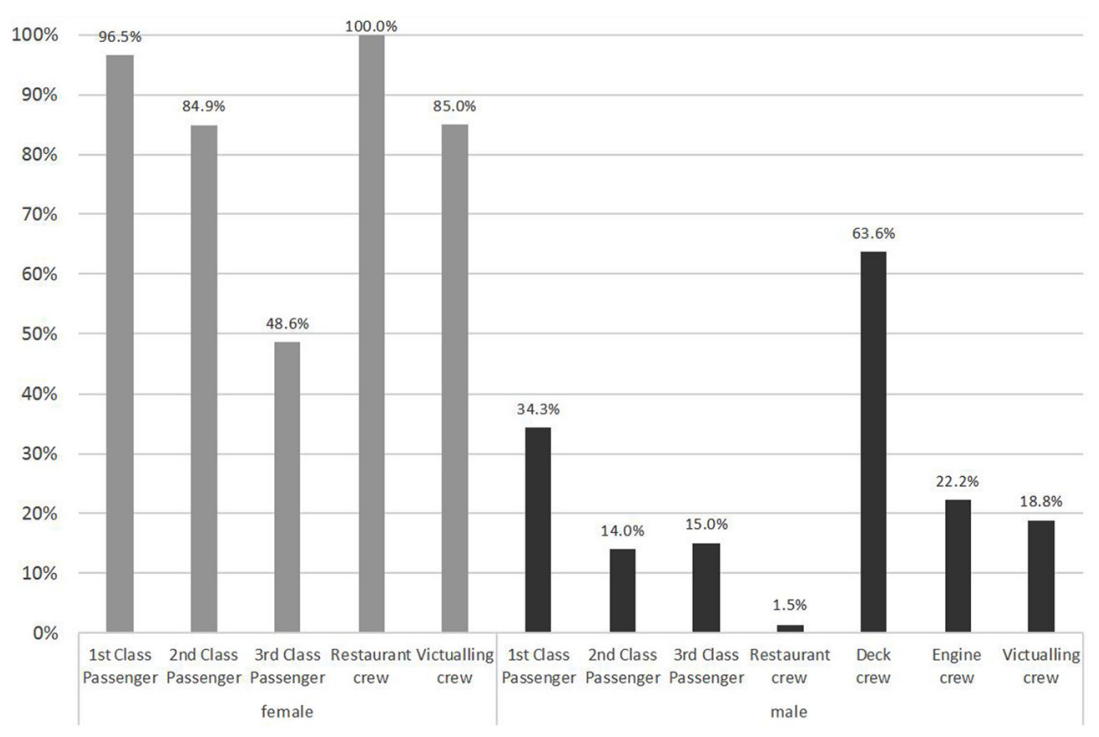

Figure I. Survival on the Titanic according to gender, class, and type of crew.

Note. Adapted from Stolz, Lindemann \& Antonietti (2018, p. 1627). Permission granted under terms of Creative Commons CC.

(1949/1968, pp. 141-143) called "general sociological orientations": a series of interlinked concepts that may guide researchers' thinking and be translated, if specified, into substantive, testable ("middle-range") theory.

\section{Social Games}

The theory of social games is based on the insight shared by scholars from different theoretical backgrounds that games-for-fun, such as tic-tac-toe and chess, seem to be miniature idealized models that depict how much of the social world functions in general. We can find this idea in the writings of Garfinkel (1967), Goffman (1961), and Coleman (1969). The fact that gamesfor-fun nevertheless contain all the necessary elements of social games in general makes them an ideal starting point for social scientific theory construction.

We define a social game as a form of organization of the social sphere that combines one or several goals, rules, representations, resources, and context and that involves interaction between various players with various attributes (Klabbers, 2018; Stachura, 2017; Swedberg, 2001). Social games include parlor games that are played "for fun," as well as all other forms of social interaction. A conversation with one's spouse, a friendship group, a mafia organization, and traffic - these are all social games. Games come in a staggeringly wide variety of forms: They may or may not have spectators, exhibit external effects, have the same goal(s) for the different players; their rules and representations may be consensual or contested, may or may not be known to all the players, and so on. Using such an extensive definition means that most social games are not played simply "for fun" and that there is nothing inherently lighthearted or enjoyable about them. Presidential elections are social games, just as are police raids and faculty meetings - all three of which are clearly not always "fun." For lack of space, we 


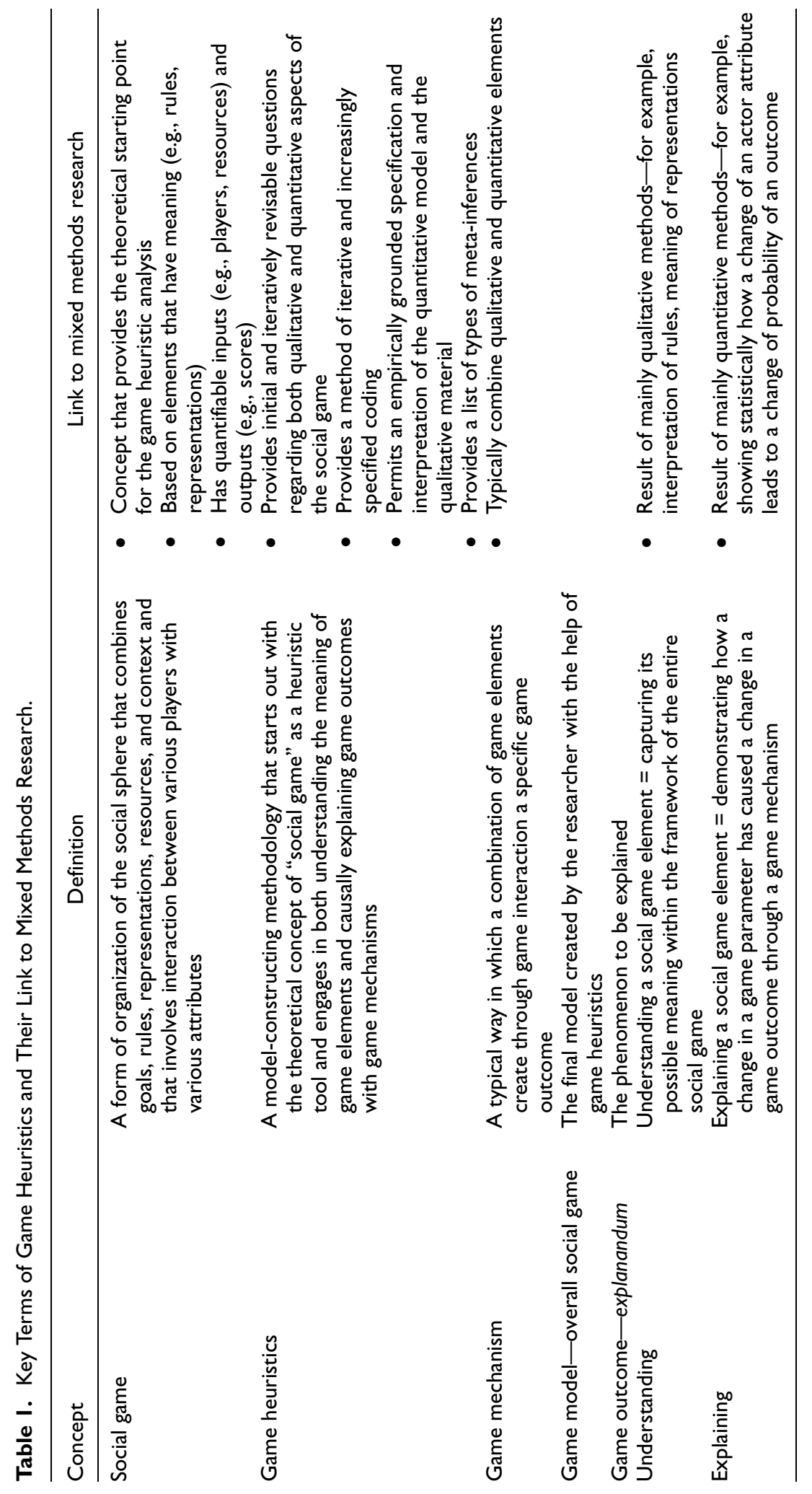


cannot give an extensive description of what the theory of social games entails. An extended treatment will be given in a forthcoming publication.

\section{Game Heuristics}

On the second level, we find game heuristics, that is the act of applying the social game perspective to a social phenomenon. We use the term heuristic in the very wide sense of a "method of discovery," a set of concepts and procedures that are thought to be fruitful in solving a problem but that do not guarantee success (Abbott, 2004). Game heuristics is a model-constructing methodology that starts out with the theoretical concept of "social game" as a heuristic tool and engages in both understanding the meaning of game elements and causally explaining game outcomes with game mechanisms.

Game heuristics assumes that the way social scientists have to learn about games is in many ways similar to how the everyday person has to learn about games (Kelle, 2007; Schütz, 1954). Imagine that you do not know cricket but would like to learn it. What can you do? You could watch a game, ask a player to explain the rules and the terminology to you, read cricket instructions, participate in a cricket game, or even try to count and note down how different observable events correlated with other events (e.g., hits and runs). You might rather quickly learn the basic rules, but it would take you longer to get the finer points to actually acquire necessary playing skills and to be able to evaluate probabilities of effects of certain actions and events. Similarly, social scientists do well to learn about social games by combining different methods.

\section{Understanding and Explaining Social Games}

Game heuristics has a straightforward way of accommodating social scientific understanding and explaining. Understanding an element of a social game (a move, a rule, a representation) means capturing its possible meanings within the framework of the entire social game. For example, I understand the chess rule "castling" if I know under what conditions and with what reasons a player may typically apply it. Understanding in this sense means understanding how others - the relevant game group - understand the game (Schütz, 1954; Wittgenstein, 2003). Explaining in game heuristics means demonstrating how a change in a game parameter has caused a change in a game outcome. A game mechanism is a typical cause-and-effect relationship in a social game. In other words, it is a typical way in which a combination of game elements creates a specific game outcome through game interaction. For example, traffic is a social game with players (traffic participants), traffic rules, representations (symbols and meanings), and so on. The fact that a traffic light changing from green to red makes participants routinely stop is a game mechanism. The fact that a new regulation setting maximum speed from 50 to 30 kilometers/hour in a given street actually lowers mean velocity of cars is another example of a game mechanism.

On the third level, we find the result of the game heuristic attempts: the final model of the phenomenon to be explained. This model describes the phenomenon as a concrete social game incorporating all the empirical assumptions concerning the context and the initial parameters necessary to permit an explanation.

\section{Social Games and Philosophical Paradigms}

Readers may wonder what philosophical paradigm the theory of social games presupposes (Creswell \& Plano Clark, 2018; Maxwell, 2010; Morgan, 2007). While we suspect that the theory of social games and game heuristics may be combined with different philosophical 


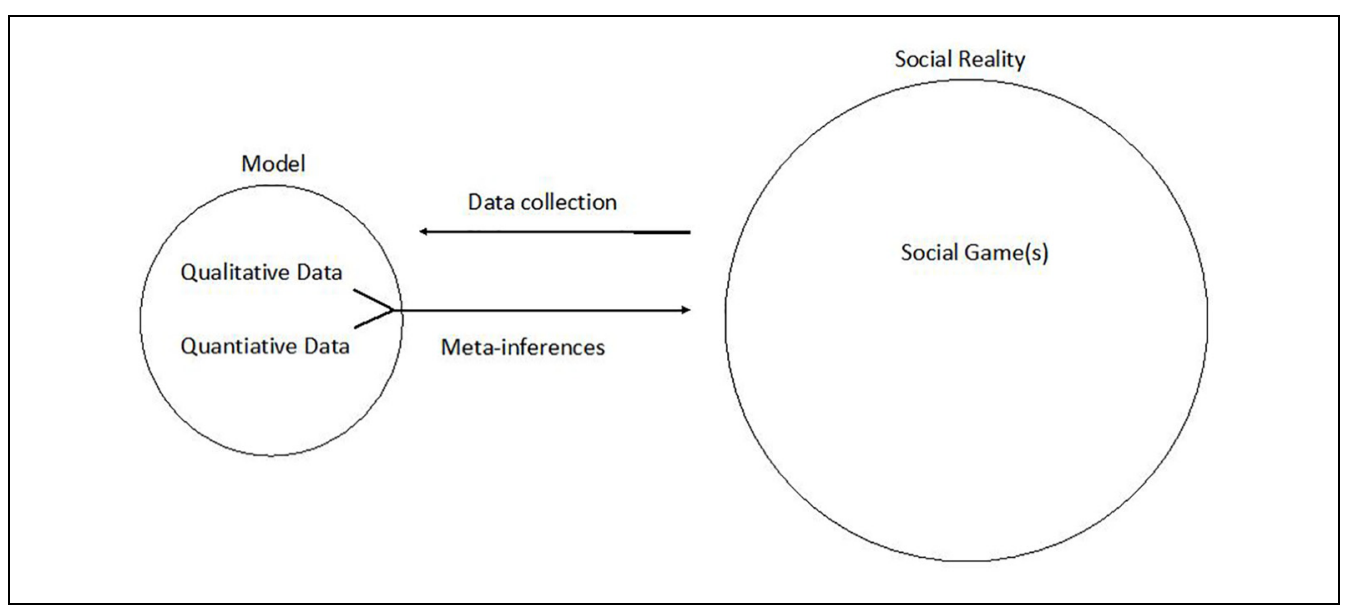

Figure 2. How mixed methods research makes meta-inferences to social games in social reality.

approaches, we take ourselves a realist stance (Brante, 2001). For our purposes, a realist approach means that we assume that social games have a reality and causal effects independently of the representations of the scientific observers - even though social games are clearly "socially constructed" in the sense that they only exist because of the representations and actions of the respective players. Social games provide opportunities to collect both qualitative and quantitative data by scientific observers who construct models by making meta-inferences about the games in social reality (Figure 2).

Note that while there are certain parallels, our approach to social games is very different from economic game theory. For example, our theory assumes that individuals' goals may change when entering a game, it does not generally assume rationality, and it insists on the importance of representations; game theory in economics on the other hand assumes fixed preferences, rationality, utility functions, and equilibria (Swedberg 2001; von Neumann \& Morgenstern, 1944/2004).

\section{Using Game Heuristics in a Convergent Mixed Methods Research Design}

Figure 3 presents a flow diagram depicting how game heuristics can work in practice in a convergent mixed methods design. In a convergent mixed methods design, the goal is to combine qualitative and quantitative data in a concurrent timing and with equal priority to profit from nonoverlapping weaknesses and strengths of the different methods (Creswell \& Plano Clark, 2018). Researchers who wish to describe and explain a phenomenon with the help of game heuristics should begin with their central question and then create an initial explanandum and a provisional model of a social game and possible game mechanisms by asking questions such as the following: Who are the relevant players and what are their most important attributes? What are the goals and rules of the game? What representations are used in the game- what do the players call the different elements, what stories do they tell about the game? What actions can the players perform, and what interactions result from their decisions? In practice, this means that researchers will begin with a model that is often rather crude but one that they will refine later through an iterative mixed methods analysis.

The next step is to carry out the quantitative and qualitative data collection, to connect and compare the data sets, and to identify and address issues of validity. 


\section{Create initial}

- research question,

- explanandum,

- social game \& game mechanisms

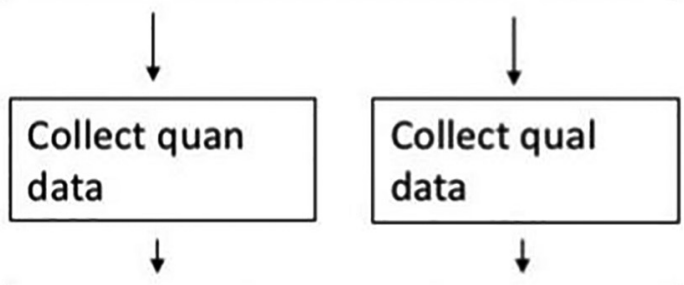

Connect and compare datasets

$\downarrow$

\section{Address validity Issues}

$\downarrow$

(Re-)construct explanandum

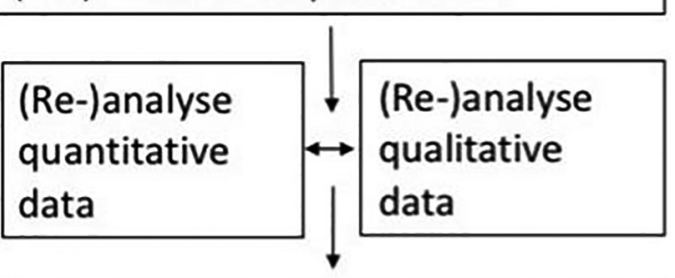

(Re-)create meta-inferences about social game

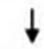

(Re-)construct overall social game \& game-mechanisms

Figure 3. Research cycle combining game heuristics and mixed methods research.

Through the iterative nature of game heuristics, we may then begin a cycle that comprises the following elements:

- (Re-)constructing the explanandum. The gradual construction of the social game may change our understanding of what we actually wish to explain.

- (Re-)analyzing our qualitative data: When using game heuristics to code qualitative data, we start out with general game categories and then (depending on our research question) slowly transform them into more specific codes for game mechanisms. 
- (Re-)analyzing our quantitative data. This includes changing the way that we set up or interpret our quantitative models, since game heuristics has led us to a better understanding of how the mechanisms work.

- (Re-)creating meta-inferences. A meta-inference can be defined as a "conclusion generated through an integration of the inferences that have been obtained from the results of the qualitative and quantitative strands of a mixed methods study" (Teddlie \& Tashakkori, 2009, p. 152). Game heuristics is useful when drawing meta-inferences, since it provides us with a model of the social reality that is supposed to have created both the quantitative and qualitative data.

- (Re-)constructing the overall social game hypothesized and the game mechanisms that are thought to have produced the explanandum.

While this outline points to the specific way in which we conducted our research on the Titanic, it may also serve as a more general template for mixed methods studies that use game heuristics in a convergent design. Of course, every study has its specificities, and we would therefore expect the outline to be adapted. For example, the (re-)construction of the explanandum may not always be present as a discrete step. Also, the number of elements in the iterative research cycle may be increased, such as when a new theoretical model prompts us to collect more data or to address new issues of validity. The key idea, however, is that the theoretical model of "social game" is iteratively specified throughout the mixed methods analysis.

\section{Game Heuristics and Other Methodologies: Similarities and Differences}

Game heuristics is somewhat similar to grounded theory when it comes to theorizing and coding, since both develop increasingly specific categories from data in an iterative manner (Corbin $\&$ Strauss, 2015). Moreover, the social game concept used in game heuristics is used in a similar way as the "coding paradigm" (consisting of conditions, interactions, strategies, and consequences) in grounded theory (Corbin \& Strauss, 2015). There are also important differences, however. Perhaps the most important difference is that in suggesting to conceptualize the social phenomenon of interest as a "social game" (or as several social games interlinked), the social game concept is theoretically more specific in its initial phase. Thus, game heuristics means focusing on elements (e.g., rules, goals) that grounded theory does not necessarily consider.

As far as integrated data analysis and the creation of meta-inferences are concerned, the use of game heuristics is very similar to what is suggested in the general mixed methods literature (e.g., Creswell \& Plano Clark, 2018; Teddlie \& Tashakkori, 2009). The main difference, however, is that game heuristics assumes that what is happening in social reality has the form of one or several social game(s). We furthermore assume that the qualitative and quantitative data (in a good research design) point to the same social game(s) and that we can therefore draw meta-inferences from those data to help us understand the underlying playing of the game. For example, if we study a traffic game, then quantitative data might show a reduction in the average speed, while qualitative data might teach us that there exist speeding rules that were changed at a certain point in time; nonetheless, both types of data would tell us about the underlying game and its game mechanisms.

Finally, we should comment on the link between game heuristics and different qualitative and quantitative methods. Game heuristics strongly argues that to understand and explain social games, we need both qualitative and quantitative types of data; however, it remains agnostic when it comes to specifying the kinds of data or techniques of analysis that are to be used. Which kinds of data and which techniques of analysis should be used depend on the problem at hand. Thus, game heuristics is certainly also compatible with techniques such as ethnography, qualitative interviewing, or qualitative comparative analysis. 


\section{Mixed Methods Design 3}

\section{Design}

The mixed methods literature distinguishes different design types (Schoonenboom \& Johnson, 2017; Teddlie \& Tashakkori 2009). Our Titanic example is similar in important ways to what Teddlie and Tashakkori (2009, p. 156) describe as a "fully integrated mixed design" in which "mixing of QUAL and QUAN approaches occurs in an interactive (i.e., dynamic, reciprocal, interdependent, iterative) manner at all stages of the study."

\section{Creating, Connecting, and Comparing the Data Sets}

The key idea formulated by Stolz, Lindemann \& Antonietti (2018) was to make a systematic link between the quantitative data set $(N=2,207)$ normally used in the quantitative analysis of the Titanic incident and a qualitative data set of testimonies provided by the survivors $(N=$ 214). Our quantitative data set $(n=2,207)$ was created from the Encyclopedia Titanica and cross-checked by various other sources in Frey et al. (2011). ${ }^{4}$ A second data set contains the testimonies of 214 survivors. These testimonies have been taken from the Encyclopedia Titanica 5 and the British and American trial proceedings. ${ }^{6}$ The survivor testimonies were grouped according to the lifeboat that enabled the individual to survive.

The two data sets are linked in two major ways. First, they are linked at the level of the individuals concerning individual names as well as all our dependent and independent variables. We also linked the data sets through the concepts measured in both data sets. This was done by specifying the different possible game mechanisms leading to the outcome, and then both recoding the quantitative variables and coding the testimonies with respect to these same game mechanisms.

\section{Dependent Variables}

We use time of boarding a lifeboat and survival (yes/no) as our central dependent variables. It was (almost) impossible to survive the Titanic incident without boarding a lifeboat at one point or another. Since we can reconstruct the time that each lifeboat left the Titanic, and since it is known (in most cases) which passengers were taken into a lifeboat from the Titanic and which from the water, we can estimate the points in time when the survivors entered the lifeboats.

\section{Independent Variables}

The independent variables are as follows:

- Gender (male, female).

- Age is a continuous variable and has been analyzed in this form in many of our models. For greater simplicity, we use two dummies in the models presented: one for age $<15$ (a child as defined on the Titanic), and one for being 51 and older. The reference category comprises all other ages.

- Class and type of crew are distinguished in one variable with attributes "1st class," "2nd class," "3rd class" for passengers and "restaurant crew," "deck crew," "engine crew," and "victualling crew" as different types of crew. Officers are coded as "deck crew." We introduced this variable into the survival analysis with dummies, the victualling crew being the reference category.

- Country of residence was recoded as two dummies representing "English" and "American." Other nationalities are the reference category. 
- Social ties were measured by two dichotomous variables: "single/not single," and "with children/ without children."

- Side of boat is a dichotomous variable that distinguishes individuals that entered boats on the port side (on the left) and on the starboard side (on the right). This variable is not used in the regression analysis since it strongly correlates with the filling of lifeboats in different phases.

\section{Qualitative Content Analysis}

Our qualitative content analysis is inspired by techniques suggested by Mayring (2014) and was conducted with MAXQDA. Starting with our research question, we developed a coding scheme inductively that consists of 29 codes, grouped under our five hypotheses. Once the coding scheme was stable, all the material was systematically recoded according to this scheme. All codes have an explicit coding rule. This allows us to quantify our qualitative data and count, for example, how many survivors in our qualitative data set from different classes experienced difficulties when trying to reach the boat deck.

\section{Validity Issues}

There are validity issues with these testimonies that are extensively discussed in Stolz, Lindemann \& Antonietti (2018). Quite obviously, the testimonies stem from a nonrandom sample of survivors - individuals selected by the process we want to explain. The testimonies themselves are equally subject to various possible bias, such as limited recall, strategic recounting of events, and others. A strength of mixed methods lies in being able to address these issues with the help of integrated data analysis. Thus, we can compare the percentages of passengers/crew with survivors and testifiers and judge the extent of selection bias. Furthermore, we can triangulate survivor accounts among themselves and integrate qualitative and quantitative findings so as to get a picture of the game process that counters possible bias as much as possible.

\section{Mixed Methods Data Analysis and Meta-Inferences}

We will now show how we used game heuristics in our research on the Titanic to inform the five steps in the iterative research cycle depicted in Figure 3.

\section{Creating the Explanandum}

Working with game heuristics changed how we constructed our explanandum in the course of the analysis. We started out with the research question of why men and women passengers in first, second, and third classes, as well as crew, survived or perished. Through our data analysis, however, we came to understand two things that led us to reconstruct our explanandum. First, we understood that the category of "crew" did not represent a homogeneous block; rather, it comprised very different functional groups with widely differing probabilities of survival. This led us to differentiate the dependent variable by distinguishing different types of crew. Second, we noticed the importance to survival of arrival time on the boat deck and the fact that it was virtually impossible to survive without boarding a lifeboat. This led us to change our explanandum from whether or not an individual survived to when exactly an individual boarded a lifeboat. 
Table 2. Early and Final Coding Scheme (Selection).

Early coding scheme: General game categories (selection)

Attributes_Resources

- Attr_Gender

- Attr_Class

- Attr_Nationality

- Attr_Lifebelts

Rules

- Filling rules

- Authority rules

- Rules for different classes

Representation/perceptions

- Repr_Impact

- Repr_Titanic

- Repr_Lifeboats

Actions/strategies

- Go up to boat deck

- Enter lifeboat

- Sneak_into_lifeboat

- Refuse_to_leave_Titanic

- Jump_into_water

Interaction/process

- Int_Stages/Time

- Int_Crowd_Size

- Int_Crew_Organizing

Context

- Cont_Localization

- Cont_Space
Final coding scheme: Specific game mechanisms (selection)

Filling_Rules

- Women\&childrenfirst

- If no more women fill up

- Couples first

- Fill with anybody

- Women shortage

- Women hesitate/refuse

Authority acceptance

- Officers in charge

- People calm, follow orders

- People excited

- Men try to sneak into boats

- Men try to rush boats

- Officers reestablish order

- Officers shoot

Way to boat deck

- Arrival time on deck

Arrives before 0.40

Arrives $0.40-1.20$

Arrives 1.20-2.05

Arrives after 2.05

- Attributes way to boat deck

On first deck when impact

Informed through crew

On other deck first

Difficult way to boat deck

Crowd obstructs passage

Crew obstructs

Reluctant to go to boat deck

Finds gate locked

Finds gate open

\section{Coding and Interpreting the Qualitative Material}

Coding in game heuristics means, just as in grounded theory, "conceptualizing, reducing, elaborating, and relating" the qualitative data (Corbin \& Strauss, 2015, p. 12). Coding always begins with the central categories of a social game as the first overarching categories. Our initial "sensitizing concepts" (Blumer, 1969/1998, p. 147) were as follows: actors and their attributes, rules, resources, representations, action, interaction, context. By using these initial codes, we can ensure that all the necessary elements of a game are treated in some way or another. However, it does not preclude creating any other code, nor does it mean that all game categories have to be present in the final coding scheme. The goal of the coding is to work slowly toward the creation of specific game mechanisms that might have created the outcome. We can see an example of early coding in Table 2, where the general game codes are still visible in the left-hand column alongside the final coding scheme with its game mechanisms in the righthand column. 
We can provide an initial example of how this worked. We started out with the general game category "Rules" and a number of different types of rules used on the Titanic. One such type became the generic code of a central game mechanism (Filling_Rules, with six subcodes) in our further coding. This game mechanism describes what rules of filling were used for a specific lifeboat, how this rule was interpreted, and under what conditions the mechanism operated. And we can provide a second example. We came across in the early phase a code "Go up to boat deck." When we continued our coding, this evolved into a mechanism that we called "Way to boat deck" that included a description of all the important attributes of the route to the boat deck (nine subcodes) and the arrival time on the deck (four subcodes).

Two tricks of the trade are useful in finding the mechanisms during the coding. The first is to consider precisely what elements of a parlor game would be needed to re-create the most important game dynamics. This technique helps us abstract the necessary elements of the game and its mechanisms from the very rich social reality shown in qualitative data. The second technique is to consider precisely what observable differences in game elements may have created the differences in the game outcome.

\section{Setting Up and Interpreting the Quantitative Model}

One of the advantages of mixed methods is that the substantive knowledge gained through qualitative exploration may lead researchers to (1) set up and (2) interpret their quantitative models in a better (i.e., more substantively grounded) way. This is actually what happened when we worked on the Titanic case. The Titanic data set is almost always used to teach logistic regression, since it seems natural to assume that the dependent variable should be whether a person survived or not. However, extensive qualitative exploration convinced us that the drawback of previous models lay in the fact that they did not take into account the temporal sequence of events. We understood how important it was precisely when individuals were informed, how much time they took to reach the boat deck, and when they finally arrived there. We therefore decided to set up a survival analysis using the time of boarding a lifeboat as our central dependent variable.

We used the survival package in R (Fox, 2008; Thomas \& Reyes, 2014) to estimate the coefficients of a Cox proportional hazard regression (survival analysis). For lack of space, we cannot describe the statistical modeling in detail but, instead, only present the full model from Stolz, Lindemann \& Antonietti (2018, p. 12; Table 3). This model distinguishes three different phases when the probabilities for different types of actors may vary (explained variance: $35.5 \%$; concordance: .789). In the substantive article (Stolz, Lindemann \& Antonietti, 2018), the model is interpreted in the following way:

- "Women have a higher survival probability than men.

- Class/type of crew remains a very strong predictor, although its influence is mediated by gender and its influence changes over time. Third-class passengers and restaurant crew have a lower, and deck crew a higher, survival probability.

- Adults of 51 and older have a lower survival probability.

- Being a child increases the survival probability for males much more than for females; and children who travel as third-class passengers have a higher survival probability than adult third-class passengers in the third phase.

- Third-class female passengers have a significantly lower survival probability than other women.

- First-class passengers, especially men, have a significantly higher survival probability in the first phase." (p. 13) 
Table 3. Cox Proportional Hazards Regression on the Time That Survivors Boarded Lifeboats (Survival Analysis).

\begin{tabular}{lc}
\hline Variable & Coefficient $^{\text {b }}$ \\
\hline Gender & $2.76 * * *$ \\
Child & 0.050 \\
I class & -0.083 \\
2 class & -0.295 \\
3 class & $-0.458^{* *}$ \\
Restaurant crew & $-1.559^{* *}$ \\
Deck crew & $1.819^{* * *}$ \\
Engine crew & 0.113 \\
Victualling crew (ref) & - \\
Age: 5 I + years & $-0.500^{* *}$ \\
Gender * child & $-1.54 I^{* * *}$ \\
Gender * I class & -0.257 \\
Gender *3 class & $-1.130^{* * *}$ \\
I class * I phase & $3.797 * * *$ \\
I class * 2 phase & 0.488 \\
Child * 2 phase & 0.934 \\
Child * 3 phase & $1.597 *$ \\
I class * Gender $*$ I phase & $-2.209 * * *$ \\
I class * Gender * 2 phase & 0.297 \\
Chi-square & 34.446 \\
Global fit & 0.023 \\
$R$-square & $35.5 \%$ \\
Concordance & 0.789 \\
\hline
\end{tabular}

Note. Since we have data on all the individuals on the Titanic, there is no sampling error and therefore no need for descriptive inference. However, we can think of statistical inference as concerning the data-generating process and, thus, use it for causal inference. Adapted from Stolz, Lindemann \& Antonietti (2018, p. 1632). Permission granted under terms of Creative Commons CC.

${ }^{a} R$-square is calculated with $N=2,188$.

$\mathrm{b}_{*} p<0.05$, **p $<0.01$, ***p $<0.001$.

In general, we may conclude that the gender and class/crew effects that we observed in the bivariate perspective hold also in a multivariate survival analysis but that the specific causal structure is somewhat complex and changes over time.

In mixed methods research, these results are not interpreted directly but are used in conjunction with the qualitative results to create meta-inferences. This is what we turn to now.

\section{Constructing Meta-Inferences}

In game heuristics, meta-inferences combine insights from the quantitative and qualitative analyses to tell us something about the underlying social game. We identify seven types of metainferences that occurred in our analysis and give every time one or several examples of how they added knowledge about the underlying "social game" on the Titanic (Table 4).

Quantifying Qualitative Game Elements. The first type of meta-inference occurred when we used quantitative means to show the distributions and cross tabulations of central game elements suggested by qualitative evidence. Quantifying game elements and their co-occurrence permits researchers to establish their relative importance as well as the conditions under which they may arise. 


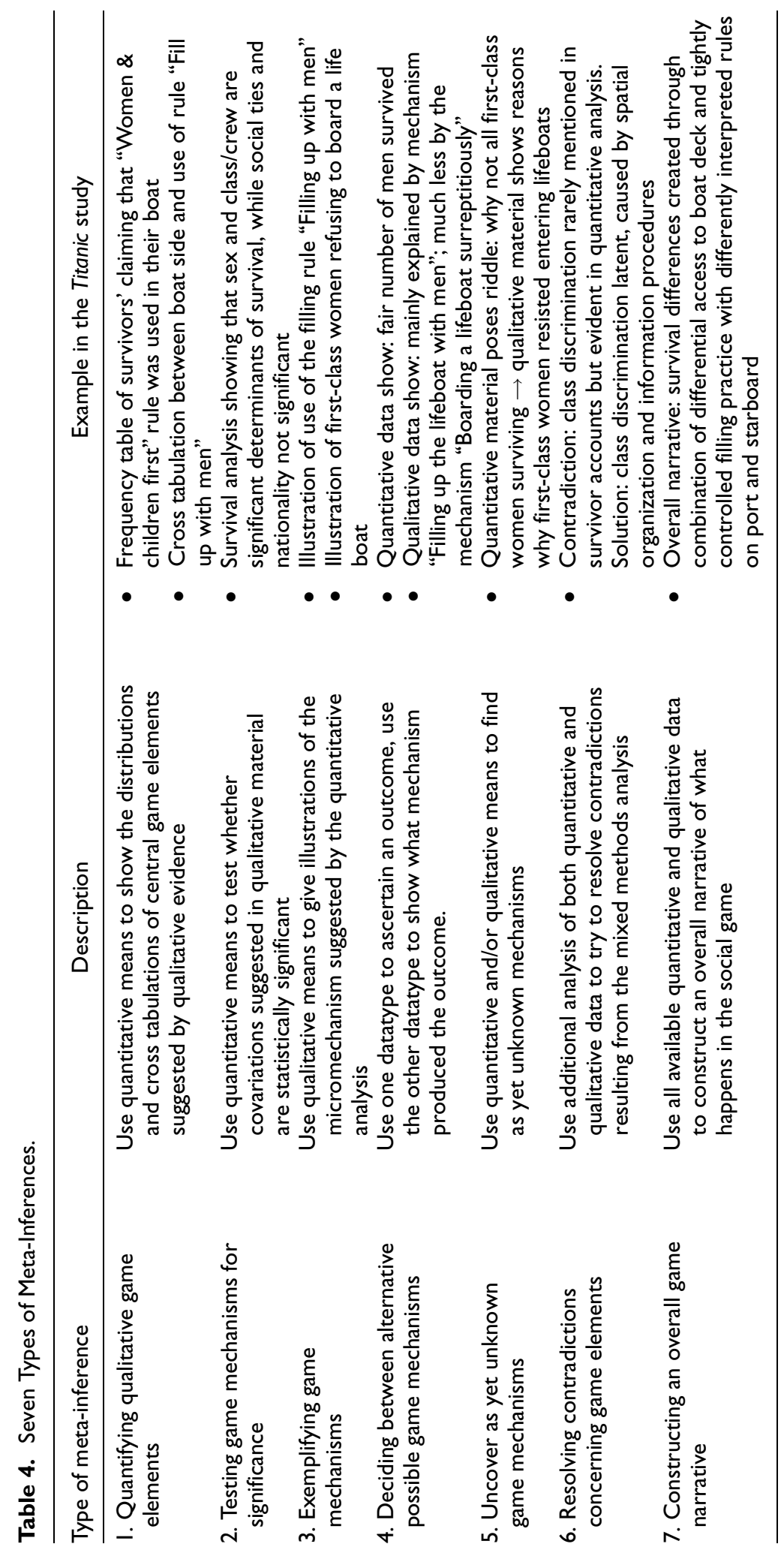


For instance, for the relative frequency in our Titanic example, when quantifying the filling rules, we are left in no doubt that the rule "Women and children first" was more important than any other filling rule on the Titanic. In fact, it is mentioned 151 times $(68.0 \%)$, as against 37 mentions of the rules "Filling up the lifeboat with men" (16.7\%), "Couples first" (6 mentions, $2.7 \%$ ), and "Fill up with anybody" (28 mentions, 12.6\%). Just as important, cross tabulations permitted us to show under what conditions game mechanisms were in action. We can see in Table 5 that according to those providing a testimony, the filling rule "Women and children first" was used in all lifeboats except the last two. We can also see important differences, however. According to those providing a testimony, other rules seem to have been used for the first two boats and the fifth boat to leave. For many boats, there were not enough women in the vicinity to fill the boats, and in some cases, the boats were "filled up with men." A closer inspection shows that it was almost exclusively on starboard (the right-hand side, facing forward) that lifeboats were "filled up with men," and that this can be explained by pointing to the fact that the officer in charge on starboard (Murdoch) interpreted the rule "Women and children first" as meaning, if no more women or children are in the vicinity, then "Fill up the lifeboat with men." However, the officer in charge of most of the lifeboats on port (the left-hand side, facing forward; Lightoller) interpreted the rule strictly - that is, as meaning that only women and children may board the lifeboats. In fact, the difference in interpretation has such a strong effect that more women than men boarded a lifeboat on port, while the reverse is true on starboard (Figure 4).

Testing Mechanisms for Significance. A second type of meta-inference permitted us to calculate whether or not the game mechanisms suggested by the qualitative material were statistically significant. This type of meta-inference is useful because relying only on qualitative evidence might lead us erroneously to see causal mechanisms at work where there is - in fact - only chance.

For example, the Titanic testimony data suggest that women were saved more often than men - due to the rule "Women and children first." Through quantitative analyses, we were able to show in both a bi- and a multivariate way that this effect is substantially important and statistically significant both in bi- and multivariate models (see Table 3). To give another example, the testimonies alone would have left us in doubt as to whether there was a class effect, since many of those providing a testimony claimed that class had played no role at all in the rescue efforts. The quantitative analysis, however, shows substantially important and highly significant class effects.

Exemplifying Typical Game Mechanisms. A third type of meta-inference showed what typical game mechanisms (suggested by both qualitative and quantitative evidence) looked like in specific instances. This meta-inference is useful because it provides a microfoundation for the game mechanism by showing how concrete actors in concrete contexts use rules, resources, and actions when reacting to given situations. With a number of concrete examples, our confidence in the validity of our findings is considerably strengthened. As an example, consider one of the many coded segments that all point to the mechanism of using the rule "Fill up the lifeboat with men, if there are no more women":

My mother got in with her maid. The officer called for other women, but there were none thereabout. Then he called for men passengers. There were only about six just there, of whom I was one, and we got in. The boat was still not filled, so the officer put in some of the crew. (Thomas Cardeza, 1 class, Boat 3 ) 


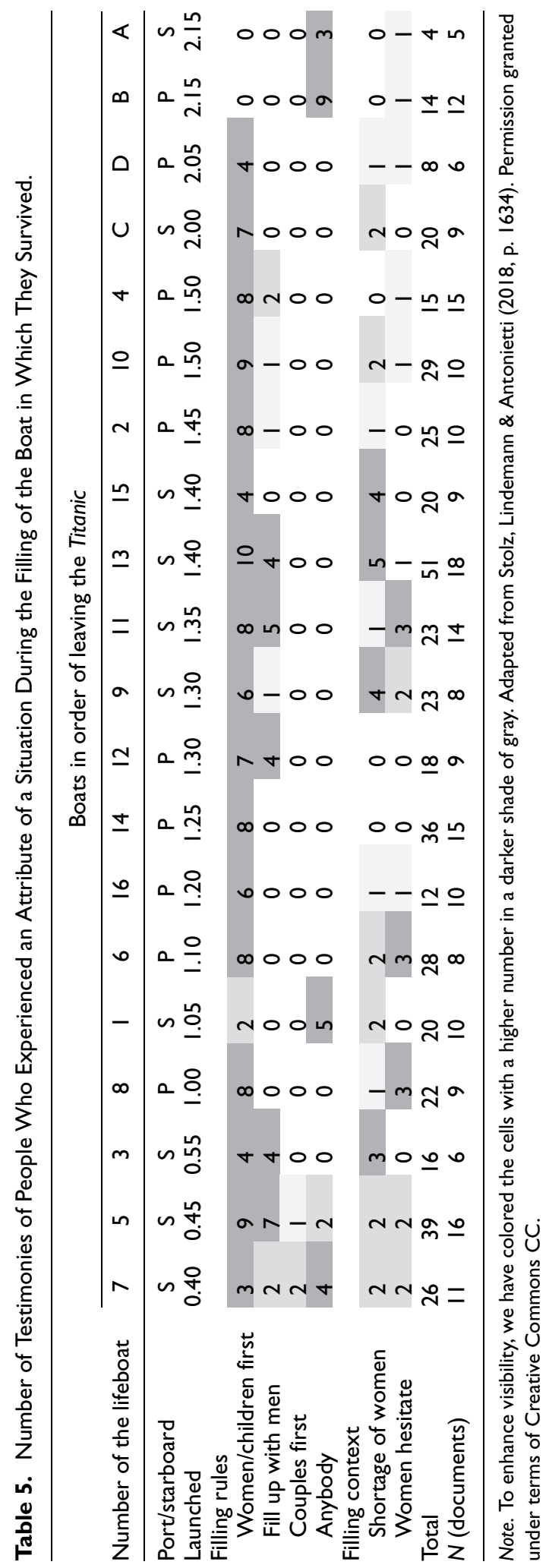



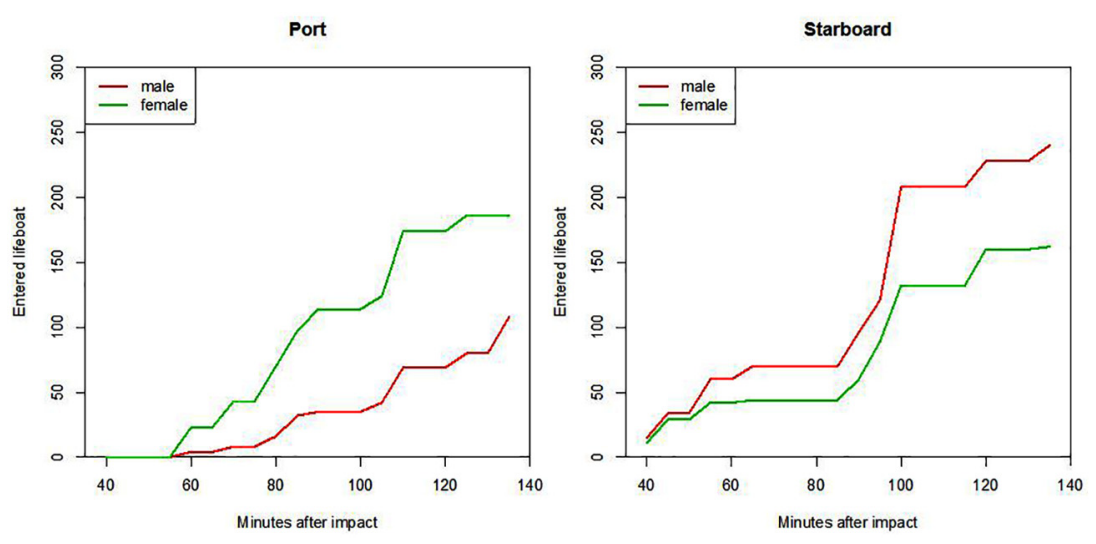

Figure 4. Women and men boarding lifeboats on port and starboard according to time after impact. Note. Adapted from Stolz, Lindemann \& Antonietti (2018, p. 1634). Permission granted under terms of Creative Commons CC.

Deciding Between Alternative Possible Mechanisms. A fourth type of meta-inference permitted us to decide which of two or more alternative game mechanisms produced a certain outcome. In such cases, an outcome is ascertained by one data type, but the question of which mechanism has produced the outcome has to be answered with the help of the other data type. In our Titanic example, the quantitative results clearly showed that quite a few men were able to survive, despite the clear rule of "Women and children first." The systematic qualitative analysis enabled us to understand that this finding was caused mainly by the mechanism of "Filling up the lifeboat with men," and much less by the mechanism "Boarding a lifeboat surreptitiously." To give another example, we can point to the fact that the quantitative analysis clearly showed that there must have been some kind of discrimination against the lower classes. But only the systematic qualitative analysis allowed us to see that this discrimination was not to be found at a manifest level when the boats were filled. Rather, it was to be found at a less visible level and was linked mostly to the fact that the cabins of the higher class passengers were closer to the boat deck, that these passengers knew their way to the boat deck, that more crew members were there to inform and help them, and that they were not hindered by crowds of people and even possibly by locked gates. We acknowledge that there might have been additional explicit discrimination against lower class passengers on lower decks. Gleicher and Stevans (2004) formulate the hypothesis that after a certain time, the crew only let women and possibly first-class passengers on the boat deck. In our view, the evidence for this hypothesis is not conclusive.

Uncover as Yet Unknown Game Mechanisms. A fifth type of meta-inference was able to uncover as yet unknown game mechanisms. In such cases, the combination of data types allows researchers to elucidate what would otherwise have remained "unexplained variance." In the Titanic example, the quantitative data showed that almost all first-class women passengers survived - but why not all of them? Our qualitative data pointed to the fact that some first-class women passengers refused to board a lifeboat because they did not consider it safe and believed that the Titanic was unsinkable. Other first-class women passengers were reluctant to leave their husbands and therefore refused to board a lifeboat. The most well-known example is Mrs. Ida Straus: 
Senator Smith: Did you know Mr. and Mrs. Straus?

Mr. Crawford: I stood at the boat where they refused to get in.

Senator Smith: Did Mrs. Straus get into the boat?

Mr. Crawford: She attempted to get into the boat first and she got back out again. . .

Senator Smith: What do you mean by "she attempted" to get in?

Mr. Crawford: She went to get over from the deck to the boat, but then went back to her husband....

Senator Smith: What followed?

Mr. Crawford: She said, "We have been living together for many years, and where you go I go." (U.S. Senate Inquiry, Day 1, Testimony of Alfred Crawford)

Resolving Contradictions Concerning Game Elements. A sixth type of meta-inference is the resolving of contradictions concerning game elements, mechanisms, or the context, resulting from the integration of the inferences of the different data types (Bazeley, 2017; Kelle, 2007). As many researchers have noted, the results of different data types may lead to contradictions. The best way of trying to solve such contradictions is often to dive deeper into the data and see if a reanalysis may provide a solution. In our Titanic example, such a contradiction emerged when we noticed that the game mechanism "class discrimination" showed up very clearly in the quantitative results but was only very rarely described in the qualitative data (and often clearly negated). The explanation - or meta-inference - we came up with is that the class discrimination was (mostly) latent, stemming from the spatial organization and the specific way that passengers were informed, rather than from manifest and conscious discrimination.

A seventh type of meta-inference concerns the overall narrative that researchers provide of what they think most probably happened in the playing out of the game based on their triangulation analyses. This is what we'll turn to now.

Reconstructing the Overall Social Game and Game Mechanisms. Using game heuristics iteratively had a strong effect on our theoretical game model during the research. We have to admit that our initial game model was very crude, lacking as it did several elements of the game model that we would later devise. For example, we were not aware of the fundamentally important role of the officers who oversaw the filling of the lifeboats, the point (quite obvious with hindsight) that to implement a rule such as "Women first," there had to be women around in the first place, and the importance of how rules were interpreted. As we continued with our research, read the transcripts, coded and analyzed the quantitative data, and learned about the ship, an increasingly complex and "reality-grounded" game model (our seventh type of "meta-inference") began to emerge.

The overall findings produced by this methodology are summarized in Stolz, Lindemann \& Antonietti (2018, p. 19) as follows:

Women and children survived more often than men because of the rule "women and children first", which was the one rule that officers and crew consciously applied throughout the process. Whenever a woman or a child was in sight, that passenger was allowed into the lifeboat first. However, the rule was interpreted differently on the starboard side (where the lifeboats were "filled up with men", once no more women or children were in sight) to how it was interpreted on the port side (where only women and children, and the necessary male crew member, were allowed to board a lifeboat). Higher-class female passengers survived more often than lower-class female passengers, because they were earlier to reach the boat deck. Men could survive for reasons that changed over time. In the first phase, first-class male passengers could board lifeboats, since they were the only men on the boat deck and first-class female passengers were rather reluctant to board a lifeboat. In the second phase, a number of lifeboats were lowered on the port side, which had a very strict 


\begin{abstract}
"women-and-children-only" rule, meaning that men (except those belonging to the deck crew) had a very small chance of boarding a lifeboat. The tragedy of second-class male passengers is that they had reached the boat deck by this time but were not allowed to board these boats. In the third phase, crew and third-class male passengers seem to have been both more numerous and enterprising when "filling up" and "sneaking onto" the boats, thus crowding out both first-class and second-class male passengers. . . . Discrimination against lower class passengers was not a conscious policy when filling the boats; rather, it was a combination of several mechanisms, including the fact that cabins occupied by the lower classes were much further away from the boat deck, that access to the boat deck was normally denied to third-class passengers, and that fewer stewards attended to them. It is important to note that we do not need mechanisms linked to nationality or social ties to explain the findings.
\end{abstract}

\title{
Discussion
}

In the mixed methods literature, the question of how to use theory and integrate data analysis is strongly debated (Bazeley, 2017; Creamer, 2018; Creswell \& Plano Clark, 2018; Fetters et al., 2013; Teddlie \& Tashakkori, 2009). In this article, we have shown how a new methodologynamely, game heuristics - was used to conduct mixed methods research on the Titanic incident. Drawing on the substantive analysis given in Stolz, Lindemann \& Antonietti (2018), we have described how game heuristics was used to specify the outcome to be explained, code the qualitative material, set up and interpret the quantitative model, construct meta-inferences, and reconstruct the overall process that created the different survival probabilities on the Titanic.

\section{The Contribution of Game Heuristics to the Field of Mixed Methods Research Methodology}

We have argued that game heuristics may prove to be a helpful addition to the mixed methods researchers' toolbox because it focuses not on a philosophical paradigm but on an iteratively adaptable theoretical framework. Using the concept of "social game," which is both meaning based and has quantifiable inputs and outputs, game heuristics guides both qualitative and quantitative data analyses in a series of iterative methodological steps until meta-inferences from the qualitative and quantitative data can be made to the most likely "social game" in social reality. In this way, it permits us to produce explanations that are (under certain circumstances) better adapted to the cases at hand.

Let us briefly review just how the theory of social games and game heuristics has helped us conduct our mixed methods study:

1. It has informed our research question by making us ask how the Titanic Game led to the astounding survival differences between men and women and different classes.

2. It has informed our theorizing by making us see the social process on the Titanic as a social game - leading us automatically to ask the general questions of game heuristics (e.g., who are the different types of players, what are the relevant player attributes, what are the game actions, what are the game rules, what are the game representations, what game space and time are involved, etc.). The theorizing became more empirically grounded in the course of the analysis, in that various substantive assumptions about the process were built into our game model.

3. It has led us to reconstruct our explanandum, in that we realized that the survival probabilities of different types of crew had equally to be explained.

4. It has made us realize the importance of different filling rules on starboard and port; and the importance of the way different classes differ in the way their cabins were located, how quickly they 
were informed after the collision, and how easy it was for them to access the boat deck (e.g., game space).

5. It has led us to see the importance of game time. This in turn made us change our analysis method from logistic regression to survival analysis to be able to incorporate the effect of time and to be able to model the effect of different phases.

6. It has made us understand the importance of the crew (one type of game actors) and the procedures in place.

7. It has helped us integrate quantitative and qualitative findings in such a way as to find the most likely game process. We identified seven types of meta-inferences that we used.

In the mixed methods literature, it is common to argue that mixing methods is useful because the strengths of different types of social scientific analysis can be combined, especially interpretive understanding (seen as a strength of qualitative methods) and causal explanation (seen as a strength of quantitative methods; Kelle, 2001, 2007; Teddlie \& Tashakkori, 2009). We have argued that game heuristics allows for a straightforward combination of understanding ("verstehen") and causal explanation ("erklären") because it makes us theorize and infer to a social game, a structure that is both meaning based and that can be causally explained. Just like a game of chess, the Titanic game can be understood in the meaning of its possible moves and causally explained in a specific instance. For example, we understand why typical first-class women were at first reluctant to enter lifeboats - they still believed the Titanic to be unsinkable and the small boats looked rather unsafe. And we have explained the survival rates in a counterfactual way in the sense that if a game parameter had been changed and the game was replayed (e.g., the interpretation of the filling rules), the outcome of the Titanic game would have changed in a foreseeable way.

As shown in the substantive paper (Stolz, Lindemann \& Antonietti, 2018), our combination of game heuristics and mixed methods was able to make considerable substantive progress with respect to the mainly mono-method state of the art. Specifically, we could show that nationality and social ties were not important to survival but that the survival rates were created by a timedependent combination of differential access to the boat deck for different classes, a tightly controlled filling procedure by the crew, differently interpreted filling rules on starboard and port, and the fact that not enough women were on the boat deck to always fill all boats.

Why were we able to make this progress with our combination of mixed methods and game heuristics? In our view, it is because we were able to ground our assumptions about the game being played on the Titanic empirically. In this way, we were able to better model the datagenerating mechanism - that is, the game that was actually played. Frey et al. (2011), who used solely quantitative methods to investigate the Titanic disaster, had to rely on assumptions that they could not verify with their data and tended to disregard the actual procedures like differential filling rules used by the crew or the spatial context. ${ }^{7}$ It is interesting to see that the other two substantive contributions - Hall (1986) and Gleicher and Stevans (2004) - use more contextual information and therefore better succeed with their explanations. Neither of these two publications, however, uses explicit mixed methods strategies to systematically link qualitative and quantitative data.

Game heuristics is admittedly a new technique, and one example where it was successfully applied does not suffice to show its general usefulness. We welcome other studies in mixed methods that work on developing game heuristics in terms of theory and methodology and examine whether and how game heuristics can be applied to other examples.

Whatever the future usefulness of game heuristics may be, we believe that the Titanic case can become as useful an example for the teaching of mixed methods as it is for the teaching of 
mainstream statistical methods, and we invite mixed methods scholars to use it freely in their teaching.

\section{Acknowledgments}

We would like to thank Jean-Philippe Antonietti for help with the statistical models. We also thank David Voas, the anonymous reviewers, and the editors for helpful comments on previous versions of this article.

\section{Declaration of Conflicting Interests}

The author(s) declared no potential conflicts of interest with respect to the research, authorship, and/or publication of this article.

\section{Funding}

The author(s) received no financial support for the research, authorship, and/or publication of this article.

\section{ORCID iD}

Jörg Stolz (D) https://orcid.org/0000-0002-3849-7812

\section{Notes}

1. Similar accounts have been published by the same authors in other journals. This has been criticized, see http://freyplag.wikia.com/wiki/FreyPlag_Wiki.

2. We had to solve specific problems when writing this article as a companion article to our substantive article. Our goal was to demonstrate the use of game heuristics in association with mixed methods as applied in the Titanic research. However, this only became interesting when presenting enough of the substantive case (bearing the risk of repeating ourselves). We therefore tried to strike a balance to find the right amount of substantive material taken from the other article; we thank the editors for guidance on this issue.

3. This methods section overlaps with the methods section in the companion article Stolz, Lindemann \& Antonietti (2018).

4. We thank David A. Savage for letting us use these data.

5. https://www.encyclopedia-titanica.org

6. http://www.titanicinquiry.org/about.php

7. Note that we do not want to debunk the researchers who have used quantitative-only methods; rather, our point is only that in certain cases mixed methods may be advantageous.

\section{References}

Abbott, A. (2004). Methods of discovery: Heuristics for the social sciences. New York, NY: W. W. Norton.

Bazeley, P. (2017). Integrating analyses in mixed methods research. London, England: Sage.

Bellocco, R., \& Algeri, S. (2013). Goodness-of-fit tests for categorical data. Stata Journal, 13, 356-365. doi:10.1177/1536867X1301300210

Blumer, H. (1998). What is wrong with social theory? In Symbolic interactionism: Perspective and method (pp. 140-152). Berkeley: University of California Press. (Original work published 1969)

Brante, T. (2001). Consequences of realism for sociological theory-building. Journal for the Theory of Social Behaviour, 31, 167-195. doi:10.1111/1468-5914.00153

Coleman, J. S. (1969). Games as vehicles for social theory. American Behavioral Scientist, 1, 2-7. doi: $10.1177 / 000276426901200602$ 
Corbin, J., \& Strauss, A. (2015). Basics of qualitative research: Techniques and procedures for developing grounded theory (4th ed.). Thousand Oaks, CA: Sage.

Creamer, E. (2018). An introduction to fully-integrated mixed methods research. Thousand Oaks, CA: Sage.

Creswell, J. W., \& Plano Clark, V. L. (2018). Designing and conducting mixed methods research (3rd ed.). Thousand Oaks, CA: Sage.

Eaton, J. P., \& Haas, C. (2011). Titanic triumph and tragedy (3rd ed.). London, England: Haynes.

Fetters, M. D., Curry, L. A., \& Creswell, J. W. (2013). Achieving integration in mixed methods designs: Principles and practices. Health Services Research, 48, 2134-2156. doi:10.1111/1475-6773.12117

Fox, J. (2008). Cox proportional-hazards regression for survival data: An appendix to an R companion to applied regression. https://socialsciences.mcmaster.ca/jfox/Books/Companion-1E/appendix-cox-regres sion.pdf

Frey, B. S., Savage, D. A., \& Torgler, B. (2011). Who perished on the Titanic? The importance of social norms. Rationality \& Society, 23, 35-49. doi:10.1177/1043463110396059

Garfinkel, H. (1967). Studies in ethnomethodology. Englewood Cliffs, NJ: Prentice Hall.

Gleicher, D., \& Stevans, L. K. (2004). Who survived the Titanic? A logistic regression analysis. International Review of Maritime History, 16(2), 61-94. doi:10.1177/084387140401600205

Goffman, E. (1961). Encounters: Two studies in the sociology of interaction. Indianapolis, IN: Allen Lane.

Hall, W. (1986). Social class and survival on the S.S. Titanic. Social Science \& Medicine, 22, 687-690. doi: 10.1016/0277-9536(86)90041-9

Harrell, F. (2015). Regression modeling strategies: With applications to linear models, logistic regression, and survival analysis. New York, NY: Springer.

Kelle, U. (2001). Sociological explanations between micro and macro and the integration of qualitative and quantitative methods. Forum: Qualitative Social Research, 2(1). doi:10.17169/fqs-2.1.966

Kelle, U. (2007). Die Integration qualitativer und quantitativer Methoden in der empirischen Sozialforschung. Theoretische Grundlagen und methodologische Konzepte [The integration of qualititative and quantitative methods in emperical social research: Theoretical foundations and methodological concepts]. Wiesbaden, Germany: VS Verlag für Sozialwissenschaften.

Klabbers, J. H. G. (2018). On the architecture of game science. Simulation \& Gaming, 49, 207-245.

Kohler, U., \& Kreuter, F. (2017). Datenanalyse mit Stata. Allgemeine Konzepte der Datenanalyse und ihre praktische Anwendung. 5. Auflage [Data analysis with stata: General concepts of data analysis and their practical application] . Munich, Germany: De Gruyter Oldenbourg,.

Landau, S., \& Everitt, B. S. (2004). A handbook of statistical analyses using SPSS. London, England: Chapman \& Hall/CRC.

Lord, W. (2012). A night to remember. London, England: Penguin Books. (Original work published 1956)

Mayring, P. (2014). Qualitative Content Analysis. Theoretical Foundation and Basic Procedures. Klagenfurt. http://www.qualitative-content-analysis.aau.at/.

Maxwell, J. A. (2010). Realism as a stance for mixed methods research. In A. Tashakkori \& C. Teddlie (Eds.), Sage handbook of mixed methods in social and behavioral research (2nd ed., pp. 145-167). Thousand Oaks, CA: Sage.

Morgan, D. L. (2007). Paradigms lost and pragmatism regained: Methodological implications of combining qualitative and quantitative methods. Journal of Mixed Methods Research, 1(1), 48-76. doi: $10.1177 / 2345678906292462$

Merton, R. K (1968). Social theory and social structure. New York, NY: Free Press. (Original work published 1949)

Ruffman, A. (2013). Titanic remembered: The unsinkable ship and Halifax. Halifax, Nova Scotia, Canada: Formac.

Schoonenboom, J., \& Johnson, R. B. (2017). How to construct a mixed methods research design. Kölner Zeitschrift für Soziologie und Sozialpsychologie, 69, 107-131. doi:10.1007/s11577-017-0454-1

Schütz, A. (1954). Concept and theory formation in the social sciences. Journal of Philosophy, 51, 257-273. 
Stachura, M. (2017). Bewertungsspiele. Von der Handlungs: zur Koordinationstheorie [Evaluation games. From the theory of action to the theory of coordination]. Kölner Zeitschrift für Soziologie und Sozialpsychologie, 69(1), 1-26. doi:10.1007/s11577-016-0401-6

Stolz, J. (2016). Opening the black box. How the study of social mechanisms can benefit from the use of explanatory mixed methods. Analyse \& Kritik, 38(1), 257-286.

Stolz, J., Lindemann, A., \& Antonietti, J.-P. (2018). Sociological Explanation and mixed methods: the example of the Titanic. Quality and Quantity, 53(3), 1623-1643. doi: 10.1007/s11135-018-00830-0

Swedberg, R. (2001). Sociology and game theory: Contemporary and historical perspectives. Theory and Society, 30, 301-335. doi:10.1023/A:1017532512350

Teddlie, C., \& Tashakkori, A. (2009). Foundations of mixed methods research: Integrating quantitative and qualitative approaches in the social and behavioral sciences. Thousand Oaks, CA: Sage.

Thomas, L., \& Reyes, E. M. (2014). Tutorial: Survival estimation for Cox regression models with timevarying coefficients using SAS and R. Journal of Statistical Software, 61(1), 1-23. doi: 10.18637/jss.v061.c01

von Neumann, J., \& Morgenstern, O. (2004). Theory of games and economic behavior. Princeton, NJ: Princeton University Press. (Original work published 1944)

Wittgenstein, L. (2003). Philosophische Untersuchungen. Auf der Grundlage der Kritisch-genetischen Edition neu herausgegeben von Joachim Schulte [Philosophical investigations: Critical genetic edition Ed. v. Joachim Schulte and others]. Frankfurt, Germany: Suhrkamp. 